\title{
Kajian Literatur (Systematic Literature Review): Kendala Penerapan Sistem Pemerintahan Berbasis Elektronik (SPBE)
}

\author{
Assaf Arief \\ Dept. Teknik Informatika \\ Universitas Khairun \\ Ternate, Indonesia \\ assaf.arief@unkhair.ac.id
}

\author{
Muhammad Yunus Abbas \\ Dept. Teknik Elektro \\ Universitas Khairun \\ Ternate, Indonesia \\ m.yunus@gmail.com
}

\begin{abstract}
Electronic-based Governance System (SPBE) or known as e-government is an effort to utilize information and communication technology to support government systems and improve the effectiveness and efficiency of government institutions' performance. The implementation of e-government is expected to improve the quality of public services. E-government in the country will usually face many obstacles that can be thwarted in its application. Previous research has discussed more about the constraints of e-government implementation in developing countries. This study aims to identify the obstacles faced in the application of SPBE/e-government in developing and developed countries. This research uses systematic literature review method by Kitchenham. The literature used in this study was taken from several digital putaka, namely ACM Digital Library, IEEE Xplore, Science Direct, and Scopus. The results of the study found that constraints in its application in developing and developed countries can be categorized into seven constraints / aspects, namely IT Infrastructure, Human Resources, Policy / Legislation, Politics, Economy, Geography and Culture. These constraints can be a reference for the government to make improvements in the implementation of SPBE so that the quality of services can be better.
\end{abstract}

Keywords-SPBE; e-government, Systematic Literature Review, Public Service.

\section{PENDAHULUAN}

Teknologi Informasi dan Komunikasi (TIK) memiliki peran penting dalam kehidupan bermasyarakat. Pengembangan TIK dapat meningkatkan efektivitas dan efisiensi sistem pemerintahan yang berdampak pada layanan publik yang lebih baik. Sistem Pemerintahan Berbasis elektronik (SPBE) atau dikenal istilah e-government adalah upaya pemerintah untuk memanfaatkan teknologi informasi dan komunikasi untuk mendukung sistem pemerintah dan meningkatkan efektivitas kinerja pemerintah. Penerapan $e$ government di suatu negara tentu akan menemukan banyak kendala. Jika suatu negara tidak dapat menghadapi kendala-kendala tersebut, hal itu dapat mengakibatkan kegagalan dalam penerapannya[1], [2].

SPBE diharapkan dapat meningkatkan layanan pemerintah kepada masyarakat. Namun, dalam prakteknya penerapan e-government suatu negara biasanya akan menghadapi banyak kendala yang dapat mengakibatkan kegagalan[1],[3]. Beberapa penelitian sebelumnya yang membahas lebih lanjut tentang kendala penerapan SPBE di negara berkembang oleh[4],[5]. Bayak peneliti tertarik untuk mengembangkan investigasi dengan mengambil tema kendala dan habatan penerapan SPBE di negaranegara maju dan berkembang. Dalam proses penerapan SPBE, bahkan negara-negara maju juga menghadapi banyak kendala[6], [7].

Kajian ini bertujuan untuk mengidentifikasi kendala-kendala yang dihadapi dalam penerapan SPBE baik di negara berkembang dan maju. Makalah ini menggunakan metode Systematic Literature Review (SLR) oleh Kitchenham. Metode ini diharapkan dapat menemukan dan merangkum kendala yang dihadapi negara dalam menerapkan SPBE. Makalah ini terdiri dari lima bagian. Bagian satu menjelaskan pendahuluan. Bagian dua akan membahas landasan teori tentang SPBE/egovernment. Bagian tiga akan menjelaskan metodologi yang dilakukan yaitu dengan menggunakan SLR. Bagian empat akan merangkum hasil penelitian, dan bagian lima adalah bagian terakhir yang akan memberikan kesimpulan dan saran dari hasil penelitian.

\section{TEORI DASAR}

Perkembangan Teknologi Informasi dan Komunikasi (TIK) dalam kehidupan manusia telah mengubah cara manusia berinteraksi dalam masyarakat. Masyarakat ditransformasikan menjadi masyarakat berpengetahuan karena kemudahan mengakses informasi baik secara lokal maupun global. Perkembangan TIK juga mempengaruhi proses tata kelola. Pemerintah berusaha meningkatkan layanan kepada publik dengan mengotomatisasi sistem dan selalu berusaha berinovasi untuk menyediakan layanan dan mekanisme layanan menjadi lebih baik[8], [9]. SPBE/e-government dapat didefinisikan sebagai penggunaan TIK dengan tujuan meningkatkan efisiensi, efektivitas dan transparansi dalam pertukaran keuangan dan informasi di dalam pemerintah. e-government adalah metode yang digunakan oleh pemerintah untuk memberikan 


\section{Kajian Literatur (Systematic Literature Review): Kendala Penerapan Sistem Pemerintahan Berbasis Elektronik (SPBE)}

layanan kepada masyarakat, dengan tujuan meningkatkan efisiensi kinerja pemerintah, dan kemudahan masyarakat dalam memperoleh informasi terkait pemerintah[10], [11].

SPBE adalah istilah yang digunakan untuk menggambarkan penggunaan teknologi informasi dan komunikasi untuk meningkatkan efisiensi dan efektivitas layanan pemerintah. Definisi lain SPBE adalah bentuk komitmen dari pemerintah untuk memperkuat kemitraan antara warga negara dan sektor publik. Instansi pemerintah telah mulai menggunakan teknologi informasi untuk meningkatkan layanan pemerintah kepada publik, meningkatkan hubungan baik dengan bisnis dan industri, dan meningkatkan efisiensi dalam manajemen pemerintah. SPBE diharapkan dapat mengurangi korupsi, meningkatkan transparansi, memberikan kenyamanan yang lebih besar, meningkatkan pendapatan pemerintah, dan mengurangi biaya[10]. Sebelum ada SPBE, interaksi antara komunitas / bisnis dan pemerintah biasanya terjadi di kantor-kantor pemerintah. Namun, dengan perkembangannya, layanan pemerintah dapat diakses langsung secara online. Ada beberapa prinsip yang harus diterapkan oleh pemerintah untuk dapat berhasil dalam penerapan SPBE, yaitu penggunaan teknologi sebagai pendorong, memperhatikan realitas saat ini, dan meningkatkan partisipasi publik dalam keberhasilan penerapan SPBE.

Layanan SPBE/e-government dapat dikategorikan ke dalam 8 jenis[12]-[14]:

1. Pemerintah-ke-Warga Negara (G2C)

Menyediakan layanan publik online dengan layanan elektronik untuk memberikan informasi dan komunikasi dari Pemerintah ke Masayarakatnya (Government to Citizen)

2. Masyarakat-ke-Pemerintah (C2G)

Menyediakan layanan publik online dengan layanan elektronik untuk pertukaran informasi dan komunikasi pelayanan dari Masyarakat ke Pemerintah (Citizen to Government)

3. Pemerintah-ke-Bisnis (G2B)

Meningkatkan inisiatif transaksi elektronik, seperti pengadaan elektronik dan pengembangan pasar elektronik untuk pembelian kebutuhan pemerintah, dan melakukan tender pengadaan pemerintah secara elektronik dari Pemerintah ke bisnis/swasta (Government to Business).

4. Bisnis-ke-Pemerintah (B2G)

Meningkatkan inisiatif e-transaksi, seperti eprocurement dan pengembangan pasar elektronik untuk pembelian kebutuhan pemerintah, dan melakukan tender pengadaan pemerintah secara elektronik untuk penjualan barang dan jasa berupa layanan dari Bisnis/Swasta ke Pemerintahan (Business to Government).

5. Pemerintah-ke-Karyawan (G2E)

Inisiatif untuk memfasilitasi manajemen layanan pegawai dan komunikasi internal dengan pegawai pemerintah dengan mengembangkan aplikasi dan layanan e-karir dengan mengurangi penggunaan kertas dengan sistem e-office berupa layanan pemerintah ke pegawainya (Government to Employee)

6. Pemerintah-ke-Pemerintah (G2G)

Menyediakan komunikasi dan kolaborasi online antara departemen lain dalam pemerintahan untuk meningkatkan efisiensi dan efektivitas berupa layanan/aplikasi (Government to Government)

7. Pemerintah-untuk-Nirlaba (G2N)

Pemerintah memberikan informasi dan komunikasi kepada organisasi nirlaba, seperti partai politik, organisasi sosial, dan organisasi masyarakat atau non profit berupa layanan/aplikasi (Government to $N G O$ )

8. Nirlaba-ke-Pemerintah (N2G)

Pertukaran informasi dan komunikasi antara pemerintah dan organisasi nirlaba, seperti partai politik, organisasi sosial, dan organisasi masyarakat lainnya berupa layanan dari NGO ke Pemerintah (NGO to Government).

\section{METODOLOGI}

\section{A. Metode}

Systematic Literature Review (SLR) suatu istilah berdasarkan metode Kitchenham[15]. SLR adalah proses kajian literatur sistematis untuk mengidentifikasi, mengevaluasi, dan meninterpretasikan semua sumber penelitian yang relevan dengan pertanyaan penelitian tentang topik suatu penelitian. Kajian dan literatur yang berkontribusi pada SLR disebut studi utama dan studi pendukung. Tujuan dari SLR adalah untuk meringkas penelitian sebelumnya yang memiliki bukti empiris, untuk mengidentifikasi kesenjangan dalam penelitian baru (research gap) untuk saran tentang penelitian masa depan dan memberikan kerangka kerja untuk memberikan arahan untuk penelitian masa depan. SLR memiliki beberapa tahapan, yaitu perencanaan, pelaksanaan, dan pelaporan. Gambar 1 mengilustrasikan tahapan dalam SLR.

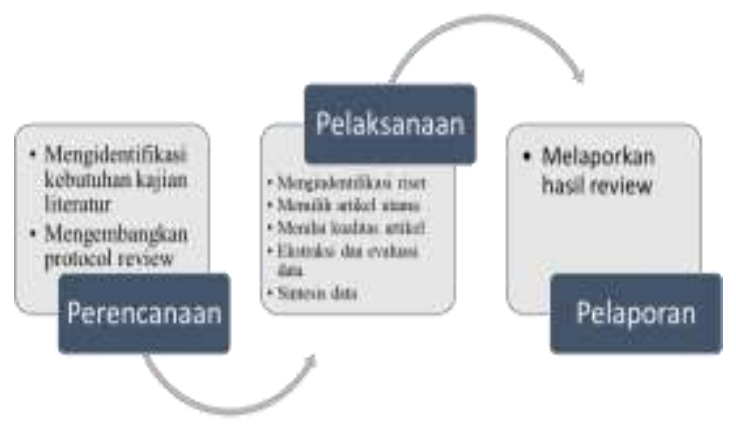

Gambar 1. Metode penelitian dengan systematic literature review (SLR).

Tahap Perencanaan terdiri dari dua fase: mengidentifikasi kebutuhan dari kajian literatur/SLR dan mengembangkan protokol peninjauan/review. Tahap pelaksanaan dimulai dengan mencari penelitian sebelumnya menggunakan beberapa database online. Hasil pencarian dikumpulkan dan diekstraksi sehingga dapat disintesis dan menghasilkan laporan penelitian. Tahap pelaporan akan menjelaskan hasil penelitian yang telah dilakukan[16]. 


\section{Kajian Literatur (Systematic Literature Review): Kendala Penerapan Sistem Pemerintahan Berbasis Elektronik (SPBE)}

\section{B. Pertayaan Penelitian (Research Question)}

SLR digunakan untuk menjawab pertanyaan penelitian yang akan dirancang. Adapun pertanyaan penelitian yang dapat diindentifikasi dari kajian literatur sebelumnya seperti dijelaskan pada point pertama dan motivasinya pada point kedua berikut:

- Pertanyaan penelitian: Apa saja kendala yang dihadapi dalam penerapan sistem $e$ government/SPBE di negara berkembang dan maju?

- Motivasi: mengidentifikasi kendala dalam penerapan sistem e-government, baik di negara berkembang maupun negara maju untuk meminimalkan kegagalan pada proses penerapannya.

\section{Strategi Pencarian}

Proses pencarian dimulai dengan mencari penelitian terdahulu menggunakan pencarian di pustaka digital. Basis data yang dipilih termasuk ACM Digital Library, IEEE Xplore, Science Direct, dan Scopus. Proses menemukan artikel ini dibagi menjadi dua tahap. Tahap pertama adalah mencari artikel ilmiah dengan kata kunci e-government atau sistem e-government, yang diterbitkan pada periode 2014 hingga 2020, dan tersedia dalam artikel lengkap. Pada tahap pertama ini, pencarian artikel juga dilakukan dengan mencari studi utama. Dari hasil pencarian di tahap pertama, 17.657 artikel dikumpulkan. Kemudian proses pengumpulan artikel memasuki tahap kedua dengan mempersempit hasil pencarian di tahap pertama dengan kriteria berikutnya bahwa artikel harus mampu menjawab pertanyaan penelitian yang telah ditetapkan sebelumnya. Pencarian dilakukan dengan metode penyaringan pada judul dan abstrak, serta memeriksa isi artikel. Hasil pengumpulan artikelpada tahap kedua menghasilkan dua puluh artikel. Proses pengumpulan artikel dapat dilihat pada Gambar. 2 berikut.

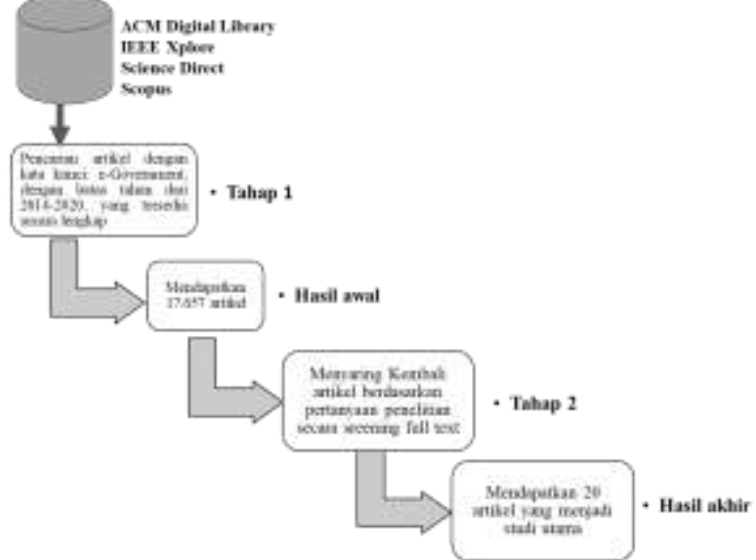

Gambar 2. Proses pencarian artikel pada studi utama.

Dari dua puluh artikel, ada lima belas artikeldalam kategori negara berkembang dan lima artikeldalam kategori negara maju. Lima belas negara berkembang yang dibahas dalam penelitian ini adalah Indonesia, Ethiopia, Dubai, Pakistan, India, Peru, Rumania, Rwanda, Sudan, Amerika Selatan, Malaysia, Yordania, Ghana, Brazil, dan Oman[17], [18]. Lima negara maju yang dibahas dalam penelitian ini adalah Jerman, Cina, Swiss, Korea, dan Canada.

Proses pemilihan artikelmenggunakan dua kriteria, inklusi dan eksklusi. Kriteria inklusi dan eksklusi yang lebih rinci dapat dilihat pada tabel I.

TABEL I. Kriteria Inklusi atau Ekslusi

\begin{tabular}{|l|c|}
\hline \multicolumn{1}{|c|}{ Kriteria } & Tipe \\
\hline Artikel memiliki kata kunci -government & Inklusi \\
\hline $\begin{array}{l}\text { Artikel publikasi di periode antara tahun2014- } \\
2020\end{array}$ & Inklusi \\
\hline Artikel dapat menjawab pertanyaan penelitian & Inklusi \\
\hline $\begin{array}{l}\text { Artikel publikasi dipilih dari database Pustaka } \\
\text { digital }\end{array}$ & Inklusi \\
\hline Artikel bukan full-text paper & Ekslusi \\
\hline Artikel publis sebelum 2014 & Ekslusi \\
\hline Menghilangkan studi yang sama atau dobel & Ekslusi \\
\hline
\end{tabular}

\section{Ektraksi dan Sintesis Data}

Setelah berhasil mendapatkan dua puluh artikelyang bisa menjawab pertanyaan penelitian, langkah selanjutnya adalah mengekstrak data. Tujuan utama dalam proses ekstraksi data adalah untuk merangkum informasi berdasarkan pertanyaan penelitian, untuk dapat pindah ke tahap berikutnya, yaitu sintesis data. Dalam proses sintesis data, hasil dari semua temuan akan dirangkum, dan pertanyaan penelitian akan dijawab berdasarkan temuan sebelumnya. Proses sintesis data dilakukan untuk menarik kesimpulan dari semua penelitian sebelumnya. Setiap penelitian sebelumnya biasanya akan menggambarkan subjektivitas dari studi kasus. Namun, dengan melakukan SLR, semakin banyak studi primer, hasil dari data sintesis akan menghasilkan pernyataan yang lebih kuat untuk menjawab pertanyaan penelitian. Pada dasarnya, metode sintesis menggunakan sintesis naratif dari semua penelitian yang telah dilakukan.

\section{HASIL DAN PEMBAHASAN}

Berdasarkan hasil ekstraksi data dalam metode SLR, kendala dalam menerapkan e-government/SPBE dapat dijelaskan pada Tabel II. Adapun kendala dalam penerapannya di beberapa negara dapat dikategorikan menjadi tujuh aspek yaitu Infrastruktur TIK, Sumber Daya Manusia (SDM), Kebijakan/Regulasi, Politik, Ekonomi, Geografis dan Budaya, seperti ditunjukan pada Gambar. 3.

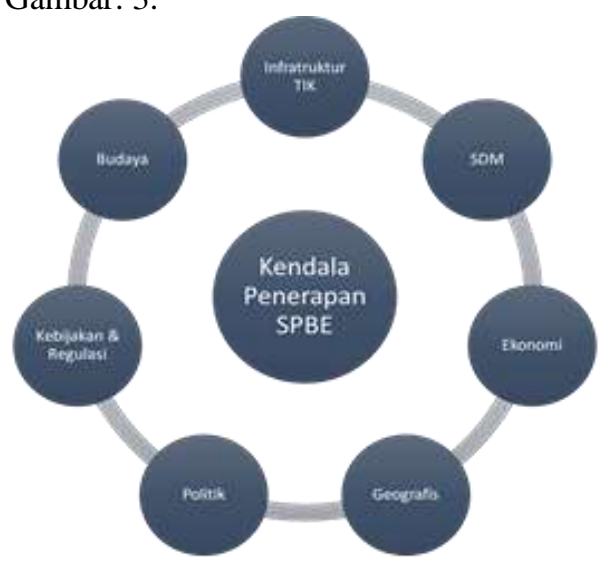

Gambar 3. Ekstraksi data kendala SPBE dari 20 studi utama. 
Kajian Literatur (Systematic Literature Review): Kendala Penerapan Sistem Pemerintahan Berbasis Elektronik (SPBE)

TABEL II. Kendala/Aspek Penerapan SPBE/e-government

\begin{tabular}{|c|c|c|c|c|c|c|c|c|c|}
\hline \multirow{2}{*}{ Referensi } & \multirow{2}{*}{ Negara } & \multirow{2}{*}{$\begin{array}{c}\text { Berkembang/ } \\
\text { Maju }\end{array}$} & \multicolumn{7}{|c|}{ Kendala/Aspek } \\
\hline & & & Infrastruktur TIK & SDM & Kebijakan & Politik & Ekonomi & Geografis & Budaya \\
\hline [19] & Indonesia & Berkembang & $\sqrt{ }$ & $\sqrt{ }$ & $\sqrt{ }$ & & & $\sqrt{ }$ & $\sqrt{ }$ \\
\hline [20], [21] & Malaysia & Berkembang & $\sqrt{ }$ & $\sqrt{ }$ & $\sqrt{ }$ & & & & \\
\hline [22] & Ethiopia & Berkembang & $\sqrt{ }$ & $\sqrt{ }$ & $\sqrt{ }$ & & & & \\
\hline [23] & Ghana & Berkembang & $\sqrt{ }$ & & & & $\sqrt{ }$ & & \\
\hline [24] & Brazil & Berkembang & $\sqrt{ }$ & & & & & & $\sqrt{ }$ \\
\hline$[5]$ & Pakistan & Berkembang & $\sqrt{ }$ & $\sqrt{ }$ & $\sqrt{ }$ & $\sqrt{ }$ & $\sqrt{ }$ & & \\
\hline$[25],[26]$ & India & Berkembang & $\sqrt{ }$ & $\sqrt{ }$ & & & & $\sqrt{ }$ & $\sqrt{ }$ \\
\hline [27] & Peru & Berkembang & $\sqrt{ }$ & & & & $\sqrt{ }$ & & \\
\hline [28] & Romania & Berkembang & & $\sqrt{ }$ & & & & & \\
\hline [17] & Rwanda & Berkembang & $\sqrt{ }$ & & & & & & \\
\hline [29] & Sudan & Berkembang & $\sqrt{ }$ & & $\sqrt{ }$ & & & & \\
\hline$[30]$ & $\begin{array}{l}\text { South } \\
\text { America }\end{array}$ & Berkembang & $\sqrt{ }$ & $\sqrt{ }$ & & & & & \\
\hline [31] & Dubai & Berkembang & & $\sqrt{ }$ & & & & & \\
\hline$[32]$ & Jordan & Berkembang & & $\sqrt{ }$ & & & & & $\sqrt{ }$ \\
\hline [33] & Oman & Berkembang & $\sqrt{ }$ & & $\sqrt{ }$ & $\sqrt{ }$ & & & \\
\hline$[34]$ & Korea & Maju & & & & $\sqrt{ }$ & & & \\
\hline$[35]$ & China & Maju & & $\sqrt{ }$ & & & & & $\sqrt{ }$ \\
\hline [36] & Germany & Maju & & $\sqrt{ }$ & $\sqrt{ }$ & & & & \\
\hline [35] & Swiss & Maju & & & & $\sqrt{ }$ & & & \\
\hline [37] & Canada & Maju & & & $\sqrt{ }$ & $\sqrt{ }$ & & & \\
\hline
\end{tabular}

Hasil ekstraksi data ini dibandingkan dengan dua penelitian sebelumnya yaitu Odat[5] dan Meiyanti[14] maka ada perbedaan pada kendala dalam menerpakan e-government. Ada lima kategori kendala yaitu Infrastruktur TI, Masalah Manajerial, Budaya Digital, Penganggaran, dan Hukum dan Perundang-undangan. Meiyanti[14] menemukan enam kategori kendala yaitu Infrastruktur TI, Masalah Manajerial, Budaya Digital, Penganggaran, Hukum dan Perundangundangan, dan Sumber Daya Manusia. Berdasarkan hasil review dari dua puluh artikel, kendala dalam menerapkan e-government dikategorikan ke dalam Infrastruktur TI, Sumber Daya Manusia, Kebijakan/Perundang-undangan, Politik, Ekonomi/ Penganggaran, dan Geografis. Studi ini menemukan tiga kendala lain, yaitu aspek politik, geografis dan budaya[38], [39].
Kendala penerapan e-government pada aspek Infrastruktur TIK adalah daya dukung pengadaan dan perawatan infrastruktur TIK yang buruk[19], lingkungan TIK yang tidak mendukung, serta kurangnya jangkauan jaringan[27], fluktuasi daya listrik, sistem yang turun dan kurangnya akses internet[14], [26].

Kendala penerapan dalam aspek Sumber Daya Manusia adalah kompetensi yang tidak memadai[14], kurangnya kesiapan di antara individu/orang untuk menggunakan layanan $e$ government, penerimaan perilaku warga negara terhadap sistem e-government, kurangnya pendidikan, kurangnya literasi digital, inisiatif kesadaran warga dan warga yang niat penggunaannya rendah terus menerus.

Kendala penerapan e-government dalam aspek Kebijakan/Legislasi adalah kurangnya koordinasi 


\section{Kajian Literatur (Systematic Literature Review): Kendala Penerapan Sistem Pemerintahan Berbasis Elektronik (SPBE)}

di antara para pemangku kepentingan, Tatakelola $e$ government yang buruk, kurangnya regulasi berupa kebijakan/undang-undang/peraturan dan kurangnya rencana strategis yang berkelanjutan.

Kendala penerapan dalam aspek ekonomi adalah kurangnya insentif dan motivasi bagi karyawan [5]dan skema pendanaan berkelanjutan untuk proyek-proyek e-government [36].

Kendala penerapan pada aspek Politik adalah kurangnya dukungan politik. Kebijakan startegis politik untuk mensukseskan penerapan sistem egovernment di masyarakat, dst.

Kendala penerapan dalam aspek geografis adalah posisi geografis yang kurang menguntungkan dari sebagian besar wilayah pedesaan dan kepulauan yang membuatnya sulit untuk menerapkan e-government [5], [25].

Kendala yang terakhir adalah budaya. Budaya yang dimaksud disini dapat berupa budaya internal organisasi itu sendiri seperti kedisiplinan, kebiasan atau cara pandang masyarakat terhadap kebiasaan dalam bekerja sehari-hari, maupun maupun motivasi dan kebiasaan masing-masing individu itu sendiri[38], [39].

\section{KESIMPULAN DAN SARAN}

Kajian literatur sistematis/SLR berdasarkan metode Kitchenham digunakan untuk mengidentifikasi kendala dalam penerapan SPBE/egovernment di negara berkembang dan maju. Penelitian dimulai dengan melaksanakan setiap tahapan berdasarkan metode Kitchenham. Tahap pertama adalah mengidentifikasi tujuan penelitian, menentukan pertanyaan penelitian (RQ), dan menentukan kriteria inklusi dan eksklusi dalam proses pencarian. Tahap kedua adalah tahap mencari artikeldari basis data ilmiah dari pustaka digital, yaitu ACM Digital Library, IEEE Xplore, Science Direct, dan Scopus. Pencarian artikel dilakukan dalam dua tahap. Tahap pertama adalah mencari artikel dengan kata kunci pencarian $e$ government, diterbitkan pada periode 2014 hingga 2020, dan tersedia dalam teks lengkap. Hasil pencarian tahap pertama menghasilkan 17.657 artikel. Tahap kedua dilakukan dengan mempersempit hasil pencarian pada tahap pertama dengan kriteria berikutnya, yaitu artikel harus mampu menjawab RQ. Hasil pencarian artikel pada tahap kedua menghasilkan dua puluh artikel yang dijadikan referensi utama. Artikel ini kemudian diekstraksi. Tahap akhir dilakukan ekstraksi data, proses sintesis serta penarikan kesimpulan hasil kajian. Hasil sintesis dua puluh artikel menunjukan kendala dalam menerapkan e-government dapat dikelompokkan ke dalam tujuh kategori yaitu Infrastruktur TI, Sumber Daya Manusia, Kebijakan/Perundang-undangan, Politik, Ekonomi, Geografis dan Budaya. Aspek ini dapat menjadi rujukan kepada pemerintah untuk dapat melakukan perbaikan dalam penerapan SPBE sehingga layanan pemerintah dapat menjadi lebih baik.

UCAPAN TERIMAKASIH
Penulis ingin mengucapakan terimakasih kepada Fakultas Teknik Universitas Khairun, Ternate, Indonesia. Terimakasih juga disampaikan kepada tim riset Smart Islands Teknik Informatika, Fakultas Teknik, Universitas Khairun.

\section{DAFTAR PUSTAKA}

[1] R. Heeks, Implementing and Managing eGovernment. SAGE Publications Ltd, 2006

[2] G. Yanqing, "E-government: Definition, goals, benefits and risks," 2010 Int. Conf. Manag. Serv. Sci. MASS 2010, pp. 9-12, 2010.

[3] P. Gunawong and P. Gao, "Understanding e-government failure in the developing country context: a processoriented study," Inf. Technol. Dev., vol. 23, no. 1, pp. 153178, 2017.

[4] A. Savoldelli, C. Codagnone, and G. Misuraca, "Understanding the e-government paradox: Learning from literature and practice on barriers to adoption," Gov. Inf. Q., vol. 31, no. SUPPL.1, pp. S63-S71, 2014.

[5] A. M. Odat, "E-Government in developing countries: Framework of challenges and opportunities," 2012 Int. Conf. Internet Technol. Secur. Trans. ICITST 2012, vol. 46, no. 2, pp. 578-582, 2012

[6] S. Y. Tan and A. Taeihagh, "Smart City Governance in Developing Countries: A Systematic Literature Review," Sustainability, vol. 12, no. 3, p. 899, 2020.

[7] R. M. Ramli, "E-government implementation challenges in malaysia and south korea: A comparative study," Electron. J. Inf. Syst. Dev. Ctries., vol. 80, no. 1, pp. 1-26, 2017.

[8] G. Viscusi, C. Batini, and M. Mercella, Information System for eGovernment, no. c. Springer, 2010.

[9] F. M. Al-Balushi, M. Bahari, and A. A. Rahman, "Defining e-Government integration and its objective: A systematic literature review," 2016 3rd Int. Conf. Comput. Inf. Sci. ICCOINS 2016 - Proc., no. October 2017, pp. 1318,2016

[10] KemanPANRB, Pedoman Evaluasi Sistem Pemerintahan Berbasis Elektronik Instansi Pusat Dan Pemerintah Daerah. 2018.

[11] Pelpres no. 95, Sistem Pemerintahan Berbasis Elektronik (SPBE). Indonesia, 2018, pp. 1-110.

[12] J. R. Gil-Garcia and T. A. P. Pardo, "E-government success factors: Mapping practical tools to theoretical foundations," Gov. Inf. Q., vol. 22, pp. 187-216, 2005.

[13] S. Angelopoulos, "New service development in egovernment: identifying critical success factors," Transform. Gov. People, Process Policy, vol. 4, no. 1, pp. 95-118, 2010.

[14] R. Meiyanti, B. Utomo, D. I. Sensuse, and R. Wahyuni, "E-Government Challenges in Developing Countries: A Literature Review," 2018 6th Int. Conf. Cyber IT Serv. Manag. CITSM 2018, no. Citsm, pp. 1-6, 2019.

[15] B. Kitchenham and S. Charters, "Guidelines for performing Systematic Literature reviews in Software Engineering Version 2.3," Engineering, vol. 45, no. 4ve, p. $1051,2007$.

[16] B. Kitchenham and P. Brereton, "A systematic review of systematic review process research in software engineering," Inf. Softw. Technol., vol. 55, no. 12, pp. 2049-2075, 2013.

[17] S. Mukamurenzi, Å. Grönlund, and S. M. Islam, "Improving qualities of e-government services in Rwanda: A service provider perspective," Electron. J. Inf. Syst. Dev. Ctries., vol. 85, no. 5, pp. 1-16, 2019.

[18] M. K. Alomari, K. Sandhu, and P. Woods, "Exploring citizen perceptions of barriers to e-government adoption in a developing country," Transform. Gov. People, Process Policy, vol. 8, no. 1, pp. 131-150, 2014

[19] A. Sabani, H. Deng, and V. Thai, "Evaluating the development of E-government in Indonesia," ACM Int. Conf. Proceeding Ser., pp. 254-258, 2019.

[20] R. M. Ramli, "Challenges and issues in Malaysian egovernment," Electron. Gov., vol. 13, no. 3, pp. 242-273, 

2017.

[21] N. A. Marzuki and N. I. Arshad, "Understanding the use of e-Government portal in rural areas in Malaysia: A proposal towards a policy," 2016 3rd Int. Conf. Comput. Inf. Sci. ICCOINS 2016 - Proc., pp. 574-578, 2016.

[22] L. Lessa and A. Tsegaye, "Evaluation of the Public Value of E-Government Services in Ethiopia," Proc. 12th Int. Conf. Theory Pract. Electron. Gov. - ICEGOV2019, pp. 21-26, 2019.

[23] E. T. Tchao, E. Keelson, C. Aggor, and G. A. M. Amankwa, "E-Government Services in Ghana - Current State and Future Perspective," Proc. - 2017 Int. Conf. Comput. Sci. Comput. Intell. CSCI 2017, no. January, pp. 624-631, 2018

[24] L. C. Serra, L. P. Carvalho, L. P. Ferreira, J. B. S. Vaz, and A. P. Freire, "Accessibility Evaluation of E-Government Mobile Applications in Brazil," Procedia Comput. Sci., vol. 67, no. Dsai, pp. 348-357, 2015.

[25] M. R. Patra and R. K. Das, "Accessibility of e-Governance in rural India: A critical view point," ACM Int. Conf. Proceeding Ser., vol. 2014-January, pp. 375-378, 2014.

[26] P. Kumar, "ICT in Local Self Governance: A Study of Rural India," Int. J. Comput. Appl., vol. 83, no. 6, pp. 3136, 2013.

[27] R. A. R. Ayquipa, H. R. Enriquez, W. J. A. Huayllani, Z. H. A. Mezarina, and M. J. I. Cabrera, "Challenges in the implementation of e-government for public institutions in Peru," ACM Int. Conf. Proceeding Ser., pp. 347-351, 2019.

[28] N. Urs, "E-government development in Romanian local municipalities: A complicated story of success and hardships," Transylvanian Rev. Adm. Sci., vol. 14, no. 55, pp. 118-129, 2018

[29] M. S. Adrees, O. E. Sheta, M. K. Omer, D. Stiawan, and R. Budiarto, "A Framework of Promoting Government Services using Social Media: Sudan E-Government Case Study," J. Phys. Conf. Ser., vol. 1167, no. 1, 2019.

[30] A. Torres-Porras and H. Duarte-Amaya, "E-Government Development Index Analysis in South America Region: Challenges and Improvement Opportunities," 2018 5th Int. Conf. eDemocracy eGovernment, ICEDEG 2018, no. Cl, pp. 275-280, 2018.

[31] S. Al Marzooqi, E. Al Nuaimi, and N. Al Qirim, "Egovernance (G2C) in the public sector: Citizens acceptance to E-government systems - Dubai's case," ACM Int. Conf. Proceeding Ser., 2017.

[32] Y. A. B. El-Ebiary, "The Effect of the Organization Factors, Technology and Social Influences on EGovernment Adoption in Jordan," 2018 Int. Conf. Smart Comput. Electron. Enterp. ICSCEE 2018, pp. 1-4, 2018.

[33] M. A. Sarrayrih and B. Sriram, "Major challenges in developing a successful e-government: A review on the Sultanate of Oman," J. King Saud Univ. - Comput. Inf. Sci., vol. 27, no. 2, pp. 230-235, 2015.

[34] J. Sangki, "Vision of future e-government via new egovernment maturity model: Based on Korea's egovernment practices," Telecomm. Policy, vol. 42, no. 10, pp. 860-871, 2018.

[35] Y. Li and H. Shang, "Service quality, perceived value, and citizens' continuous-use intention regarding e-government: Empirical evidence from China," Inf. Manag., vol. 57, no. 3, p. 103197, 2020.

[36] L. Thiel, "The interplay between E-government service adoption preferences and E-government service delivery in Germany," Proc. Annu. Hawaii Int. Conf. Syst. Sci., vol. 2016-March, pp. 2913-2922, 2016.

[37] L. G. Anthopoulos and C. G. Reddick, Government eStrategic Planning and Management. Springer, 2018.

[38] T. Altameem, M. Zairi, and S. Alshawi, "Critical Success Factors of E-Government: A Proposed Model for EGovernment Implementation," 2006, pp. 1-5.

[39] P. Aasi, L. Rusu, and S. Han, "The influence of culture on IT governance: A literature review," Proc. Апnи. Hawaii Int. Conf. Syst. Sci., pp. 4436-4445, 2014. 